\title{
Assessment of control strategies and interventions against COVID-19 in selected municipalities in Luzon
}

\author{
Marsha Czarina G. Almeria ${ }^{\mathrm{a}, \mathrm{g}}$, Elisha Gabrielle P. Anacta ${ }^{\mathrm{b}, \mathrm{g}}$, Mervin Zhyrus \\ A. Artillaga ${ }^{\mathrm{c}, \mathrm{g}}$, Mary Anne B. Castro ${ }^{\mathrm{d}, \mathrm{g}}$, Ma. Frieda Z. Hapan ${ }^{\mathrm{e}, \mathrm{g}}$, Patricia Ann C. \\ $\mathrm{Jose}^{\mathrm{f}, \mathrm{g}}$
} ${ }^{\mathrm{a}}$ marshaczarina.almeria.pharma @ ust.edu.ph, ${ }^{\mathrm{b}}$ elishagabrielle.anacta.pharma @ ust.edu.ph, ${ }^{\mathrm{c}}$ mervinzhyrus.artillaga.pharma @ust.edu.ph,
${ }^{\mathrm{d}}$ maryanne.castro.pharma @ ust.edu.ph, ${ }^{\mathrm{e}}$ mzhapan@ $\mathrm{ust} . \mathrm{edu}$.ph ${ }^{\mathrm{f}}$ patriciaann.jose.pharma @ust.edu.ph

${ }^{8}$ University of Santo Tomas Faculty of Pharmacy Medical Technology, España Blvd, Sampaloc, Manila, 1008 Metro Manila, Philippines

\begin{abstract}
With the increasing number of COVID-19 infections in the Philippines, current control strategies and interventions must be re-assessed. A comparative-descriptive study was conducted to determine, compare, and suggest which of the implemented pandemic strategies, controls, and interventions against COVID-19 are effective or needs improvement and modification in order to decrease case transmissions in four municipalities from Region III and Region IV-A namely Bauan, Batangas; Bulakan, Bulacan; Mexico, Pampanga; and Sta. Cruz, Laguna. The data was gathered through an online questionnaire divided into several sections namely: Demographic Profile, Quarantine and Isolation, Social Distancing, Contact Tracing, Testing, Establishment Closure, Perceptions, Governance, and Finance and Support. Different sets of questions were answered by municipal constituents, social workers, government employees and health workers. To determine differences in the control strategies implemented, Descriptive Analysis, ANOVA with confidence level of 95\%, Chi Square Test for Independence and Pearson Correlation were utilized for data analysis and interpretation. The ratings of four municipalities in the eight categories of government control strategies and interventions were ranked to determine the strong and weak areas of each municipality. Results showed that there is a significant difference between the control strategies and interventions implemented in the municipalities of Bauan, Batangas and Sta. Cruz, Laguna while Mexico, Pampanga and Bulakan, Bulacan are not significantly different. Moreover, results of ANOVA demonstrated that there is a significant difference between the effectiveness of control strategies and interventions being implemented in the four municipalities $(\mathrm{F}=9.418$ and $\mathrm{p}<.001)$. In particular, both Bauan, Batangas and Mexico, Pampanga implement control strategies and intervention that is significantly more effective than Sta. Cruz, Laguna. Perception. The results of the Pearson Chi-Square shows that there is a significant association between the age (p-value is <0.001) and occupation (pvalue is 0.002 ) of the respondents and their perception on the effectiveness and efficacy of control strategies and interventions in their respective municipalities. Whereas, there is no significant association between the gender of the respondents are their perception on the effectiveness and efficacy of control strategies and interventions ( $p$-value is 0.656 ) in each municipality. Furthermore, suggestions in order to improve the implemented control strategies and interventions to prevent the further spread of COVID-19 were propounded.
\end{abstract}

Keywords: COVID-19; pandemic; control strategies: interventions; public health: Luzon

\section{Introduction}

The recent outbreak of the novel coronavirus or COVID-19 was first reported at the end of December 2019 in Wuhan, China. The cases of unexplained low respiratory infections were initially classified as pneumonia of unknown etiology. Local government and the government of China have organized intensive health investigation programs before attributing the said virus to the family of coronavirus. This virus was highly contagious and has quickly spread in its neighboring countries. Eventually, it has also spread globally. 
According to the World Health Organization $(2020)^{[1]}$, respiratory droplets from infected patients is one of the modes of transmission of COVID-19 virus. Since all populations are susceptible and at risk to this virus, it has easily evolved into a global pandemic after a few months in which it represents a serious public health risk.

Infectious diseases occur and spread in varying levels of frequency and regularity. The baseline or the expected level is termed "endemic" which refers to a disease usually present or constantly prevalent in a community. Irregular or infrequent occurrence of a disease is referred to as "sporadic". On the other hand, a sudden increase in the expected number of cases of a disease in a population within a geographic area is called an "epidemic". A pandemic happens when a new disease emerges and spreads worldwide.

According to the World Health Organization (2011) ${ }^{[2]}$, pandemics can occur in the temperate northern and southern hemispheres yearly, given that a huge population is affected and international boundaries are crossed. Factors considered do not include population immunity, virology, or the severity of the disease.

The coronavirus $(\mathrm{CoV})$ is one of the major pathogens of emerging outbreaks in the respiratory system. It is a large family of single-stranded RNA viruses that is isolated from various animal species which can then be transmitted to humans. The humans, when infected with the virus, may experience illness from common colds to more severe respiratory conditions. Past outbreaks of coronaviruses have been characterized as agents which pose great public health threat to the public, including severe acute respiratory syndrome (SARS)-CoV and the Middle East respiratory syndrome (MERS)-CoV.

COVID-19 has infected more people in comparison to its two pandemic predecessors: Severe Acute Respiratory Syndrome (SARS) and Middle East Respiratory Syndrome (MERS). According to the World Health Organization (2020) $)^{[3]}$, COVID-19 has shown a great significance in the health, economic, and political impact across Southeast Asia. Countries have established numerous countermeasures in response to the devastating effects brought about by this virus. Health organizations have coordinated derivatives and guidelines which would be helpful in controlling the spread of the virus. The World Health Organization has provided evidence that one of the preventive and control measures that most countries could do is the use of medical face masks as a protection for healthy individuals or for prevention of onward transmission. Regular hand washing or the use of at least $60 \%$ alcohol is also advised by the Centers for Disease Control and Prevention (CDC) as the transmission of the virus may also occur through fomites. However, it has shown that rapid containment measures in response to the virus is an effective way of mitigating its impact. Aggressive isolation measures implemented in China showed a progressive reduction in the number of cases of infection in their region. Most countries in Southeast Asia have also prioritized mass testing after putting into consideration previous outbreaks, such as SARS in 2003. Countries such as Cambodia, Malaysia, Singapore, and Thailand have a systemic free COVID-19 testing and treatment for their citizens. Although it is also evident that some countries, such as the Philippines and Myanmar, have a varying national-level testing capacity which lead to the under-detection and a lower capacity of controlling the evolution of the virus.

During a pandemic, it is undeniable that life is put into a halt. Education was hindered, businesses went bankrupt, and the workforce dwindled. With these units greatly affected, it is unarguable that the economy struggles in the face of a pandemic. In a study by Kohlscheen et al. (2020) ${ }^{[4]}$, it was proven that the persistence of a pandemic causes a global-scale economic dwindling. With spillovers occurring in the age of globalization, economic growth becomes obstructed, crippling major transactions around the regions of the world such as in the Philippines. The Philippines, known for its breath-taking tourist sites, is acknowledged as one of most rapidly growing players in the tourism industry. As tourism declines, airline services, such as in the Philippines, struggle to stay in the market. In March, Rivas (2020) ${ }^{[5]}$ reported around 30,000 cancelled flights in the Philippines alone, after the lockdown imposed by President Rodrigo Roa Duterte on March 16, 2020. Aside from the Philippines, Thailand seems to have also struggled in keeping its airline services in the market. In a report by Techaphangam $(2020)^{[6]}$, Thai Airways filed for bankruptcy protection in order for it to thrive in the market as recovering from the pandemic seems far from sight. Although, around August, 
Thailand seemed to have recovered from the rising cases of patients through the implementation of strict public health policies implemented by its authorities.

Although, as huge as the economy may seem, it is only but a cog in a wheel. It is actually those who drive the economy to the limelight who suffer the most. Throughout the pandemic, the World Health Organization $(2020)^{[3]}$ recorded around 23.9 million cases so far. With people suffering the most consequences of the pandemic, it will be difficult for the world to regain its shape — especially with the health sector struggling the most. With SARS-CoV-2 infections increasing, hospitals become filled with COVID-19 patients, leaving no room for others who need medical care. According to Roberton et al. (2020) ${ }^{[7]}$, the pandemic has indirectly affected non-COVID-19 mortality rates. With the depletion of medical resources, Roberton estimated an increase in both maternal and infant deaths in the future. From their model, they predicted an additional 253,500 children and 12,200 maternal deaths. With the predicted numbers being labeled as the "least severe scenario", the situation grows more concerning. With this projection, it is impossible to not worry about the medical sector of the Philippines. According to the Yee $(2020)^{[8]}$, the country's health sector is, in fact, suffering from the consequences of the pandemic as the system is being slowly overwhelmed by COVID-19 patients. With $57.7 \%$ occupancy rate in private hospitals and $49.5 \%$ occupancy rate in public hospitals, the health sector is not far from plummeting. The increasing demand for medical services and the declining supply for the services puts the health sector of the country in a bad position, risking the lives of not only hundreds, but thousands.

Although the occurrence of a pandemic is uncertain, it is important to be prepared with strategies and possible interventions that may be applied in the event of a sudden global outbreak. According to Ghebreyesus et al. $(2020)^{[9]}$, the faster the cases are found and isolated, the harder it will be for the virus to spread, thus saving lives and mitigating the economic impact of the pandemic. In addition, the World Health Organization (WHO) suggested that in a national level, it is important to strengthen the following: coordination of the national and subnational response, engagement and mobilization of affected and at-risk communities, implementation of context-appropriate public health measures to slow transmission and control sporadic cases, preparation of the health system to reduce mortality, maintain essential health services, protect health workers, and contingency planning to ensure continuity of essential public functions and services.

The Pan American Health Organization (PAHO) (2020) $)^{[10]}$ prescribed municipal and individual level interventions to limit the spread of a pandemic. On an individual level, good handwashing practices decrease the amount of virus that may spread through hand shaking and touching surfaces. If unavailable, individuals can carry their own hand sanitizers and alcohols. It is also recommended for individuals to keep their distance, separate the sick, and cover coughs and sneezes to prevent the spread of respiratory droplets. On a community level, temporary closure of public establishments as well as schools and offices should be implemented. This way, the risk of transmission will be lessened. If closure is not feasible, the observance of social distancing in and out of the offices should strictly be observed. These interventions will be effective in reducing the risk of transmitting the virus only if collective effort from individuals and the community is applied.

\subsection{Statement of the Problem}

In a report by Esguerra $(2020)^{[11]}$ in August, the Philippines alone had the most cases of COVID-19 infections in Southeast Asia. With a total of 119,460 infections in the early half of 2020, the country is now being dubbed by its neighboring countries as the hotspot of the pandemic.

With the increasing number of cases of COVID-19 infections in the Philippines, current control strategies and interventions must be re-assessed. A comparative-descriptive study on the control strategies and interventions used in four different municipalities from the Pampanga, Bulacan, Batangas, and Laguna will be 
conducted in order to determine which of the implemented practices need to be improved and modified in order to reduce case transmissions.

Specifically, this study aimed to answer the following questions:

1. What pandemic strategies and contact tracing and isolation procedures are implemented in the four different municipalities from the Region III and Region IV-A?

2. Which of the identified contact tracing and isolation procedures is the most effective in decreasing the transmission of COVID-19?

3. Do demographic factors affect the perception of residents in the effectiveness and efficacy of control strategies and interventions implemented in municipalities covered in this study?

4. What can the researchers suggest in order to improve the implemented control strategies and interventions to prevent the further spread of COVID-19?

5. What other important insights and other significant statistical facts can be inferred from this study which can further help in mitigating COVID-19 transmissions?

\subsection{General Objectives}

1. To determine which of the numerous, implemented mitigation strategies from several municipalities in the Philippines are effective and efficient in decreasing case transmissions of COVID-19 infections,

2. to assess the existing control strategies and interventions implemented against the spread of COVID-19 infections,

3. to determine whether demographic factors affect the perception of residents in the effectiveness and efficacy of control strategies and interventions implemented in their respective municipalities; and

4. to come up with suggestions for the improvement of current mitigation strategies and isolation procedures in combating the COVID-19 pandemic.

\subsection{Specific Objectives}

1. To determine from which municipalities in Pampanga, Bulacan, Batangas, and Laguna have the most effective and efficient mitigation strategies and isolation procedures in response to the COVID-19 pandemic,

2. to determine which municipalities in Pampanga, Bulacan, Batangas, and Laguna have ineffective and inefficient mitigation strategies and isolation procedures in response to the COVID-19 pandemic,

3. to assess the effectiveness of current COVID-19 contract tracing and surveillance in municipalities from Pampanga, Bulacan, Batangas, and Laguna,

4. to assess the effectiveness of imposed quarantine protocols against the COVID-19 pandemic in municipalities from Pampanga, Bulacan, Batangas, and Laguna; and

5. to assess whether age, gender, and occupation affect the perception of residents in the effectiveness and efficacy of control strategies and interventions implemented in their respective municipalities.

\subsection{Hypothesis}

1. There is no significant difference between the control strategies and interventions of municipalities from Pampanga, Bulacan, Batangas, and Laguna against the COVID-19 pandemic.

2. There is no significant difference between the number of new COVID-19 cases in the municipalities from Pampanga, Bulacan, Batangas, and Laguna on periods with noticeable changes or marked consistencies.

3. There is no significant difference between the effectiveness of control strategies and interventions of municipalities from Pampanga, Bulacan, Batangas, and Laguna against the COVID-19 pandemic. 
4. Age, gender, and the occupation of residents in the municipalities do not affect the perception of residents in the effectiveness and efficacy of control strategies and interventions implemented in their respective municipalities.

\subsection{Conceptual Framework}

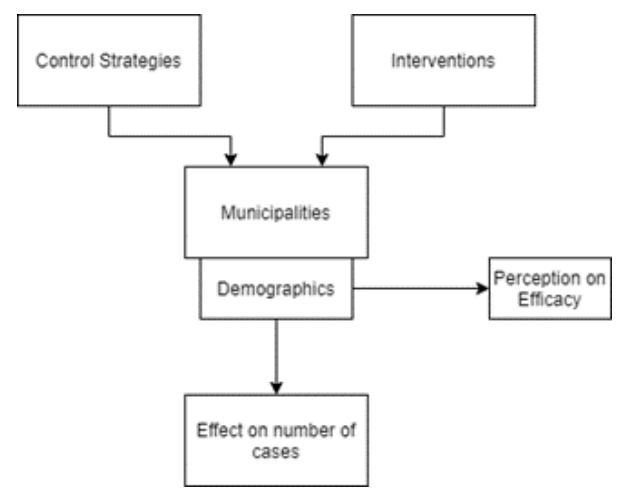

Fig. 1. Conceptual Framework of the Study

The conceptual framework (Figure 1) was adapted from the study conducted by Prasetayo et al. (2020) ${ }^{[12]}$ in which it outlined the integration of the theories in determining the causal relationships between the variables in order to evaluate the factors that affects the perceived effectiveness of COVID-19 prevention measures among Filipinos residing in Luzon. In their study, they have used different hypothesis which presents the perceived effects on the behavior and attitude of Filipinos towards COVID-19. However, unlike the study mentioned, the conceptual framework (Figure 1) developed in this study used the control strategies, interventions, and demographic factors of the four municipalities in evaluating its effectiveness towards the number of COVID-19 cases.

\subsection{Significance of the Study}

The COVID-19 pandemic has progressed rapidly which constitutes a challenge for most communities, especially the vulnerable populations. Various strategies and control measures have been recommended by health departments in reducing the potential exposure of people from the virus. Based on the past pandemics, contact tracing and patient isolation is a key strategy in preventing further spread of COVID-19. The response of communities towards these strategies varies due to the differences and inequalities of each city.

This study provides an overview on the efficiency and effectiveness of the different patient isolation and contact tracing procedures deployed in various municipalities in Pampanga, Bulacan, Batangas, and Laguna during the COVID-19 pandemic. The data that was gathered from this study was utilized to identify the control measure that will potentially enhance the response in the increasing number of COVID-19 cases. In the assumption that existing control strategies and interventions against the COVID-19 pandemic are ineffective, then the use of other existing models of interventions must be recommended.

The following people and institutions may benefit after the completion of the study:

The academe. The findings from this study will allow the further development and research on the efficient and effective measures concerning viruses. 
The local government units. The study will help local government units in establishing control strategies and interventions in response to the current pandemic, and act as a foundation for pandemic preparedness in the future.

The government. The results of the study will be of significance in increasing the national familiarity and management of virus infections. This will also enable the government in applying immediate response to future pandemics.

The health sector. The results generated from this study will allow health institutions in applying the appropriate clinical monitoring and isolation procedures in order to mitigate the worsening of the virus.

Future researchers. This study will allow future researchers to conduct new studies which will confirm the findings acquired and evaluate its possible application in future pandemics. This study can also be used by future researchers as a reference for their studies.

\subsection{Scope and Limitations}

The scope of the study is confined to comparison of patient isolation and contact tracing of several municipalities in Pampanga, Bulacan, Batangas, and Laguna. The study delved into their reported cases, data and patient isolation and contact tracing strategies combating COVID-19 pandemic. Respondents who participated in the study include municipal constituents, social workers, government employees and health workers from the aforementioned municipalities. Other municipalities were not considered in the analyses, except only when theories need to be given light to elucidate concepts.

\section{Research Elaborations}

\subsection{Research Design}

This study utilized a quantitative and comparative-descriptive research design. The study was descriptive in nature as it utilized descriptions in determining which among the implemented mitigation strategies from four municipalities are truly effective and efficient in decreasing case transmissions of COVID-19 infections. Moreover, this study is comparative in nature for it intended to determine if there is a significant difference between the control strategies and interventions particularly in the categories of social distancing and testing employed by each municipality.

\subsection{Subjects and Study Site}

The participants of the study involved four hundred eighty-five (485) respondents that are either residents, social workers, local government officials, or healthcare workers that are residing in municipalities in the provinces of Batangas, Bulacan, Pampanga, and Laguna. The municipalities in which the study was conducted are as follows: Bauan, Batangas; Bulakan, Bulacan; Mexico, Pampanga; and Sta. Cruz, Laguna. The respondents in each municipality are aged between 15 to 64 years old. Non-probability sampling, specifically snowball sampling was done in the selection of the respondents wherein the researchers requested for referrals in recruiting respondents that are fit with the criteria.

The sample size was three hundred eighty-five (385) which was determined through the Cochran equation (1).

$$
n=\frac{1.96^{2}(0.5)(1-0.5)}{(0.05)^{2}}
$$


The sample proportion was based on the rate of population in different age groups, whereby distribution of the respondents per occupation depends. Across three hundred eighty-five (385) respondents in each municipality, most of the respondents were from Mexico, Pampanga.

Table 1. Sample Proportion of the Four Different Municipalities from Region IV-A and Region III

\begin{tabular}{ccccc}
\hline \multirow{2}{*}{ Age } & Bulakan, Bulacan & Bauan, Batangas & Sta. Cruz, Laguna & Mexico, Pampanga \\
\cline { 2 - 5 } & & & Population & 30,876 \\
\hline 15 to 24 & 14,022 & 16,801 & 21,932 & 24,794 \\
25 to 34 & 12,378 & 15,399 & 18,331 & 21,012 \\
35 to 44 & 10.461 & 12,266 & 15,922 & 16,202 \\
45 to 54 & 8,781 & 9,820 & 12,627 & 9,867 \\
55 to 64 & 6,191 & 6,473 & 7,494 & 102,751 \\
\hline Total & 51,833 & 60,759 & & 292,649 \\
\hline Grand Total & & & 0.2641594538 & 0.3511066158 \\
\hline p & 0.1771166141 & 0.2076173163 & 101.7013897 & 135.1760471 \\
\hline
\end{tabular}

\subsection{Data Instrumentation}

The research instrument utilized in this study is in the form of an online questionnaire formulated by the researchers. The validity of the questions with responses in the Likert scale were tested with the use of Pearson Product Moment Correlation. Furthermore, the reliability of scale ratings was tested with the use of Cronbach's Alpha Reliability Test.

The first part of the online questionnaire included the socio-demographic profile of the participants including their name, age, gender, address or municipality where they're residing, and their occupation. The second part of the questionnaire was divided into different sections such as quarantine and isolation, social distancing, contact tracing, testing, establishment closure, governance, perceptions, and finance. This research instrument was formulated from different memoranda, protocols, and research from the World Health Organization (WHO), Department of Interior and Local Government (DILG), and the Department of Health (DOH). Specifically, the questions were derived from DOH's Budget Briefer 2021; DILG's Guidelines on LGU Budgeting, Procurement, and Fund Utilization for COVID-19 Response and Recovery Interventions Pursuant to "Bayanihan to Recover as One Act"; Department Memorandum No. 2020-0439, "Omnibus Interim Guidelines on Prevention, Detection, Isolation, Treatment, and Reintegration Strategies for COVID19" by DOH and WHO's Pandemic Influenza Preparedness in WHO Member States: Report of a Member States Survey.

\subsection{Data Gathering and Ethical Considerations}

Survey questionnaires were disseminated through the use of Google Forms as the main platform for data gathering. Prior to the administration of the survey questionnaire, consent forms stating that they are willing 
to continue their participation in the study. The researchers were in charge of sending the link of the online questionnaire to the email provided by the respondents of the study. The study conducted non-probability sampling, specifically snowball sampling. The initial respondents were also asked to disseminate the survey to their families and friends that fits the criteria of the study. The response of each respondent was directed and collected by Google Spreadsheets, wherein responses not meeting the criteria were filtered by the researchers. The data gathered from the online survey were then subjected to statistical analysis using the Microsoft Excel and SPSS software.

The researchers conducted the survey to four hundred eighty-five (485) respondents that are either residents, social workers, local government officials, or healthcare workers that are residing in municipalities of Bauan, Batangas; Bulakan, Bulacan; Mexico, Pampanga; and Sta. Cruz, Laguna. Non-probability, snowball sampling was used in the selection of the participants.

This research study has been approved by the University of Santo Tomas - Faculty of Pharmacy Research Ethics Committee. The participation of the respondents in the study only required them to answer the prepared and validated online questionnaire designed for this study. Prior to the administration of the survey questionnaire, consent forms stating that they are willing to continue their participation in the study were provided to each respondent. If inconveniences were present, the respondent were given the right to withdraw their participation from the study. The privacy and confidentiality of the respondents and all the personal information they provided during the study will remain protected and shall not be made public by the researchers in compliance with the Data Privacy Act of 2012 (Republic Act 10173). The right to access the data is only limited to the researchers, the research adviser, and peer reviewers.

\subsection{Data Analysis}

The response of each respondent was directed and collected by Google Spreadsheets, wherein responses not meeting the criteria were filtered by the researchers. The data gathered from the online survey were then subjected to statistical analysis using the Microsoft Excel and SPSS software version 26.

The demographic data gathered from the respondents of the study included name, age, gender, address or municipality where they're residing, and their occupation. These data were presented through percentages. The comparison of the strong and weak control strategies was based on computed percentage and mean obtained by the municipality per category to determine if there is a significant difference in each municipality on their categorized pandemic strategies, namely quarantine and isolation, social distancing, contact tracing, testing, establishment closure, governance, perceptions, and finance.

ANOVA was utilized to test the significant difference between control strategies employed in each municipality, specifically in the categories of social distancing and testing, as well as perceptions with a confidence level of 95\%. Moreover, post-hoc test was performed using Dunnet C, including Tukey HSD, to determine which municipality is significant from the others. To test the relationship of the demographic factors on the perception of respondents in the selected municipalities on the effectiveness and efficacy of the pandemic control strategies, Chi Square Test for Independence was utilized. Subsequently, Cramer's V was performed as a post-test to determine the strengths of association after the Chi Square Test has determined the significance. 


\section{Results or Findings}

\subsection{COVID-19 Cases}

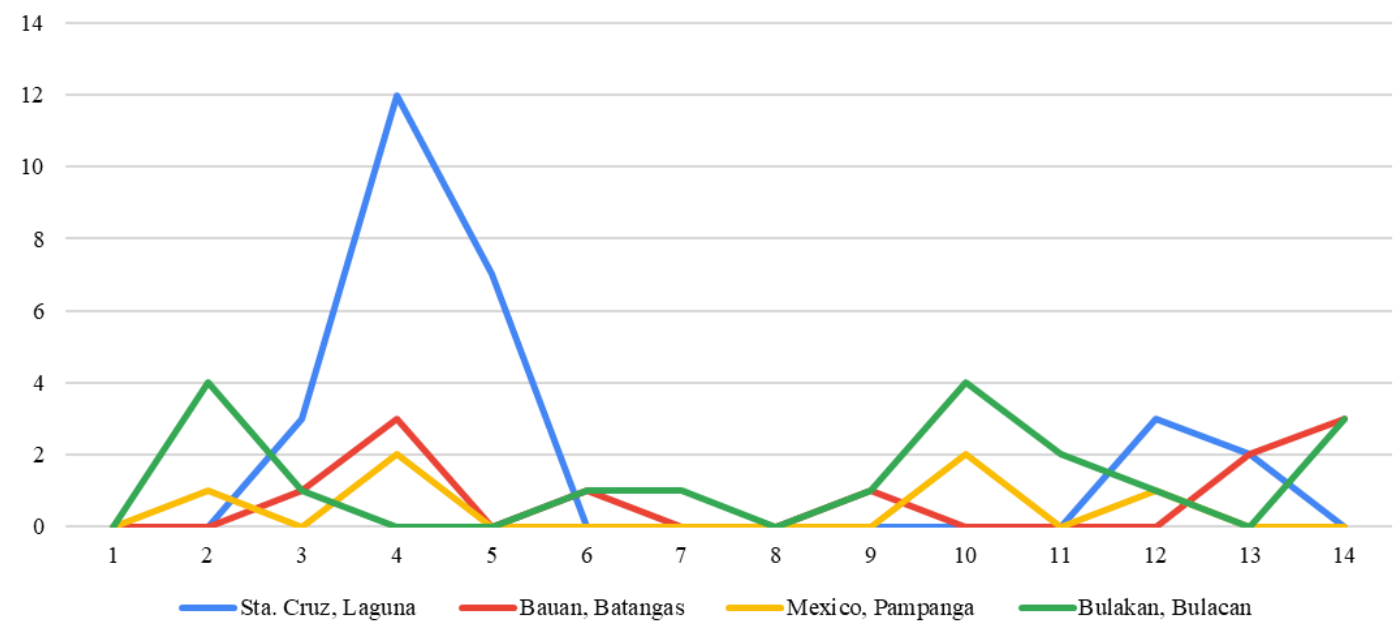

Fig 2. Number of New COVID-19 Cases from the 3rd Week of March 2020 to the 4th Week of June 2020

Figure 9 shows the number of new COVID-19 cases per week, covering the 3rd week of March 2020 to the 4th week of June 2020. Mexico, Pampanga maintained its curve below Bulakan; Bulacan, Bauan, Batangas; and Sta. Cruz, Laguna most of the time.

Sta. Cruz, Laguna has its noticeable peak with 12 new cases at week 4 and declined gradually on week 6 . It maintained a plateau of zero cases from week 6 to week 11, then peaked at 3 cases on week 12 .

Bauan, Batangas has a fluctuating up and down trend with its peak points at the 4th, 6th, and 9th week. It somehow maintained its plataeu with number of cases ranging from 0 to a maximum of 3 .

Table 2. ANOVA: Number of New COVID-19 Cases from the 3rd Week of March 2020 to the 4th Week of June 2020

\begin{tabular}{lllll}
\hline & df & $\mathrm{F}$ & P-value & Interpretation \\
\hline Between Groups & 3 & 1.443 & .241 & Not significant \\
Within Groups & 52 & & & \\
Total & 55 & & \\
\hline \multicolumn{4}{c}{ Level of Significance: 0.05}
\end{tabular}

The result of ANOVA shows that there is no significant difference between the means of the number of new cases of four municipalities during the first 14 weeks covering the period of the 3rd week of March 2020 to last week of June $2020(\mathrm{~F}=1.443, \mathrm{p}=.241)$. 


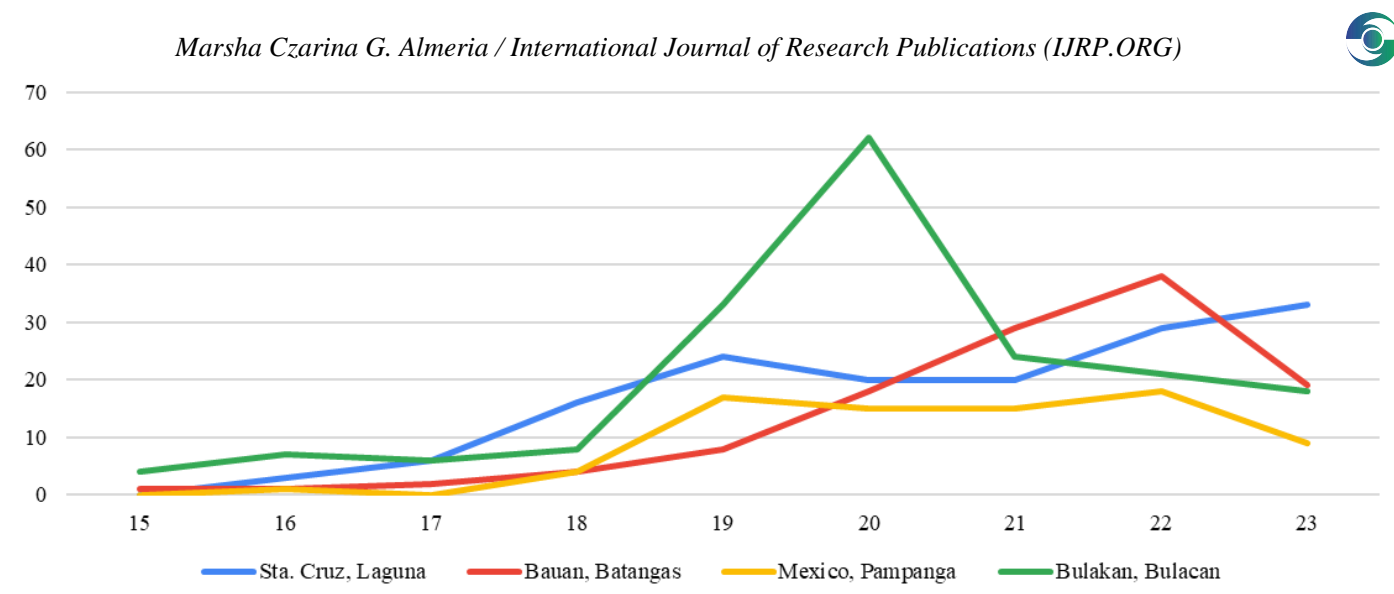

Fig 3. Number of New COVID-19 Cases from the 1st Week of June 2020 to the 1st Week of September 2020

Sta. Cruz, Laguna gradually increases starting from week 15 to week 19 with its peak on week 19 at 24 new cases. It declined for a period of two weeks and went up on the 21st week. Its curve is consistently higher than the curves of Mexico and Bauan, Batangas from week 15 to week 20.

Mexico, Pampanga has maintained a plateau of zero cases for two weeks, then gradually increased starting from week 17 to week 19. It kept a plataue curve from week 19 to week 22 and declined on week 22. Its graph is consistently below the graphs of Sta. Cruz, Laguna and Bulakan, Bulacan from week 15 to week 23.

Bauan, Batangas has a gradual increase in the number of cases from week 15 to week 22 with its peak on week 22 at 38 new covid cases. It was able to keep its curve below Sta. Cruz, Laguna and Bulakan, Bulacan from week 15 to week 20. It went above the graph of the other two municipalities from week 20 to 22 .

Bulakan, Bulakan has a gradual increase from week 15 to week 18 and noticeably peaked at 62 on the 20th week and then declined starting from the 20th week.

Table 3. ANOVA: Number of New COVID-19 Cases from the 1st Week of June 2020 to the 1st Week of September 2020

\begin{tabular}{lllll}
\hline & df & F & P-value & Interpretation \\
\hline Between Groups & 3 & 1.443 & .241 & Not significant \\
Within Groups & 52 & & & \\
Total & 55 & & & \\
\hline
\end{tabular}

Level of Significance: 0.05

The result of ANOVA shows that there is no significant difference between the means of the number of new cases of four municipalities during the 15 th week to the 23 rd week $(F=1.225, \mathrm{p}=.317)$. 


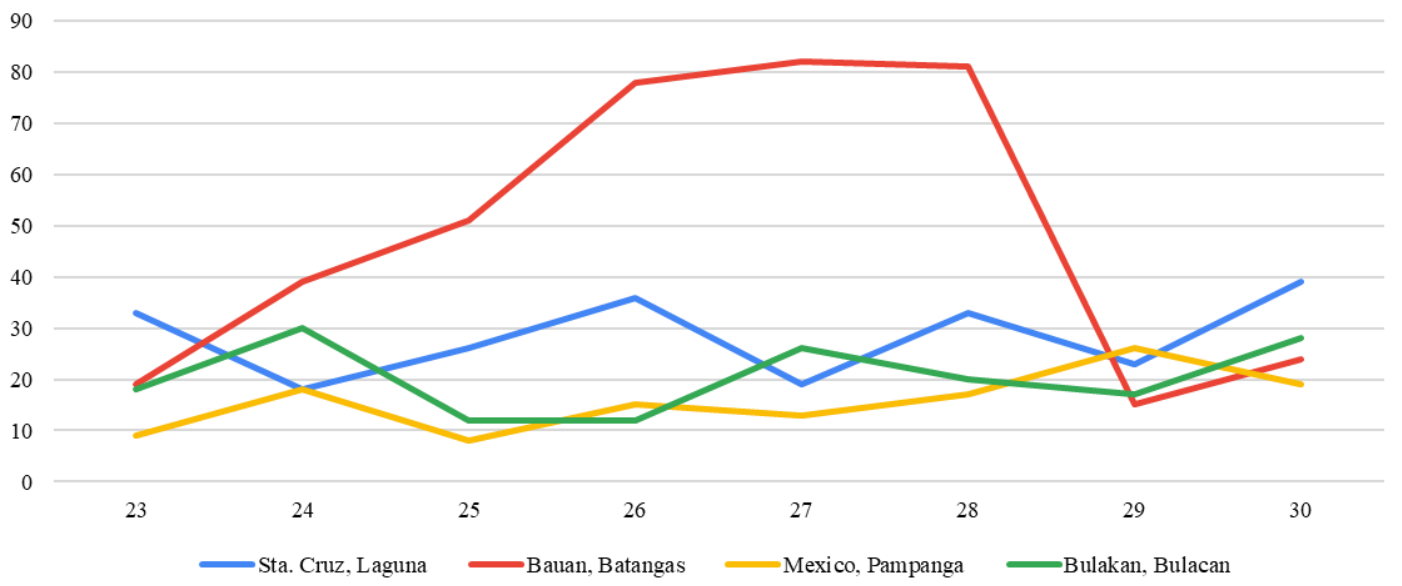

Fig 4. Number of New COVID-19 Cases from the 1st Week of September 2020 to the 1st Week of November 2020

Mexico, Pampanga had the lowest mean number of new cases of 15.63 with a standard deviation of 5.805. A low standard deviation indicates consistency and less variability in the number of cases which is coherent with the graph in keeping a plataeu from week 23 to week 30. It is consistently below the curve of Sta. Cruz, Laguna which suggests that Mexico, Pampanga exhibited a more effective in controlling the spread of the virus than Sta. Cruz, Laguna.

Bauan, Batangas interestingly has a more dispersed graph indicating high variability compared to other municipalities. There is a rapid increase of number of cases from week 23 to 26 but maintained a plateau for two weeks after that. On week 29 , there was a significant abrupt decrease in the number of cases while maintaining a curve below Bulakan, Bulacan and Sta. Cruz, Laguna until the 30th week. This indicates effective strategies and interventions for the significant decline in the number of cases on week 29.

Sta. Cruz, Laguna remained above the curve of Bulakan, Bulacan most of the time during the period of week 25 to week 30. This means that most of the time duriing the period of week 23 to week 30, there are more new cases in Sta. Cruz, Laguna than Bulakan, Bulacan. This may indicate more effective strategies and interventions being implemented in Bulakan, Bulacan than Sta. Cruz, Laguna. However, result of the post hoc test indicated no evidence of significant mean difference.

Table 4. ANOVA: Number of New COVID-19 Cases from the 1st Week of September 2020 to the 1st Week of November 2020

\begin{tabular}{lllll}
\hline & df & F & P-value & Interpretation \\
\hline Between Groups & 3 & 1.443 & .241 & Not significant \\
Within Groups & 52 & & & \\
Total & 55 & & \\
\hline \multicolumn{5}{c}{ Level of Significance: 0.05}
\end{tabular}

Result of the ANOVA shows that there is a significant difference between the mean number of new cases of each municipality $(\mathrm{F}=7.034, \mathrm{p}=.001)$.

The result of post hoc Tukey HSD test suggests that the mean number of new cases of Bauan, Batangas is significantly different than Mexico, Pampanga and Bulakan, Bulacan with $p$ values of .001 and .006 respectively. A very high standard deviation of Bauan, Batangas resulted to non-homogeneity of the municipalities, hence Dunnet $\mathrm{C}$ was also used for the post hoc test. Result of post hoc test using Dunnet $\mathrm{C}$ for 
unequal variances resulted that mean number of cases of Mexico, Pampanga is significantly different than that of Sta. Cruz, Laguna.

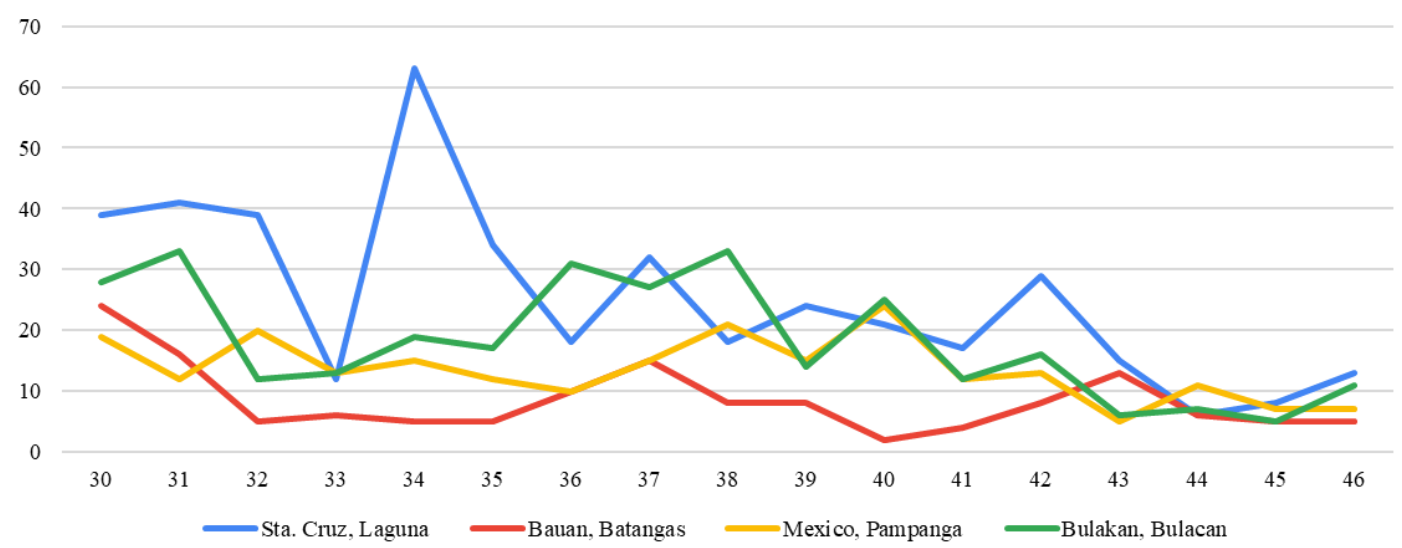

Fig 5. Number of New COVID-19 Cases from the 1st Week of November 2020 to the 1st Week of March 2021

During the period of week 30 to week 46, the graph of Bauan, Batangas is, most of the time, below the graphs of the other three municipalities. It declined during week 30 to week 32, maintained a plateu for 3 weeks, gradually decrease from week 37 to week 40, and then increase gradually for a period of 3 weeks. It then exhibited a gradual decrease until week 46.

Mexico, Pampanga is below the graph of Sta Cruz, Laguna and Bulakan, Bulacan from week 30 to week 43 most of the time. From week 39 to week 43, the graph of Mexico, Pampanga coincides with that of Bulakan, Bulacan. This may indicate that Mexico, Pampanga has more significantly effective strategies and interventions than Bulakan, Bulacan and Sta. Cruz, Laguna. Similarly, the graph of Bulakan, Bulacan is below the graph of Sta. Cruz, Laguna from week 30 to week 35 and from week 39 to week 46.

The graph of Sta. Cruz, Laguna shows evidence of fluctuations with its peak points on weeks 31, 34, 37 and 42; and week 34 at a significant high point. It also shows inconsistent behavior and variability on the number of new cases.

Table 5. ANOVA: Number of New COVID-19 Cases from the 1st Week of November 2020 to the 1st Week of March 2021

\begin{tabular}{lllll}
\hline & df & F & P-value & Interpretation \\
\hline Between Groups & 3 & 1.443 & .241 & Not significant \\
Within Groups & 52 & & & \\
Total & 55 & & \\
\hline \multicolumn{5}{c}{ Level of Significance: 0.05}
\end{tabular}

The result of ANOVA suggests significant difference between the means of new cases $(\mathrm{F}=9.418, \mathrm{p}$ $<.001)$. Post hoc result suggests that the mean of Bauan, Batangas is significantly different than the mean of Bulakan, Bulacan and Sta. Cruz, Laguna. Furthermore, the mean of Mexico, Pampanga is significantly different than the mean of Sta. Cruz, Laguna but not significantly different than Bauan, Batangas and Bulakan, Bulacan.

Hence, there is a significant difference between the effectiveness of control strategies and interventions being implemented in the four municipalities during this period of week 29 to week 46 . In particular, both 
Bauan, Batangas and Mexico, Pampanga implement control strategies and intervention that is significantly more effective than Sta. Cruz, Laguna.

3.2. Pandemic Strategies, Contact Tracing, and Isolation Procedures Implemented in Four Municipalities from Region III and Region IV-A

The ratings of four municipalities in the eight categories of government control strategies and interventions were ranked to determine the strong and weak areas of each municipality. Control strategies and interventions ranked as first and second were considered as strong areas, while those with ranks of third and fourth were considered as weak areas.

Table 6. Ranking of Municipalities

\begin{tabular}{lccccc}
\hline & Bauan, Batangas & Bulakan, Bulacan & Mexico, Pampanga & Sta. Cruz, Laguna & Perfect Score \\
\hline 1. Quarantine and Isolation (Rating score) & 2 & 3 & 4 & 1 & 5 \\
2. Social Distancing & 1 & 3 & 2 & 4 & 5 \\
3. Contact Tracing & 1 & 2 & 3 & 4 & 5 \\
4. Testing & 2 & 1 & 4 & 3 & 5 \\
5. Establishment Closure & 3 & 4 & 1 & 2 & 5 \\
6. Perception & 1 & 3 & 2 & 1 & 5 \\
7. Governance & 4 & 2 & 3 & 4 & 5 \\
8. Finance & 1 & 3 & 2 & 4.00 & 5 \\
\hline \multicolumn{2}{r}{ Average } & 1.00 & 2.00 & 3.00 & 2.88 \\
\hline
\end{tabular}

As shown in Table \#, Bauan, Batangas had the most number of strong areas and least number of weak areas, followed by Mexico, Pampanga; Bulakan, Bulacan; and lastly, Sta. Cruz, Laguna. With this, there is a very noticeable difference in the number of strong areas and weak areas between Bauan, Batangas and Sta. Cruz, Laguna whereas no significant difference is observed between Mexico, Pampanga and Bulakan, Bulacan.

With reference to the strong areas and weak areas of control strategies and interventions implemented in each municipality, areas found to be significantly effective are identified based on the strong areas of Bauan Batanags and Mexico, Pampanga. 


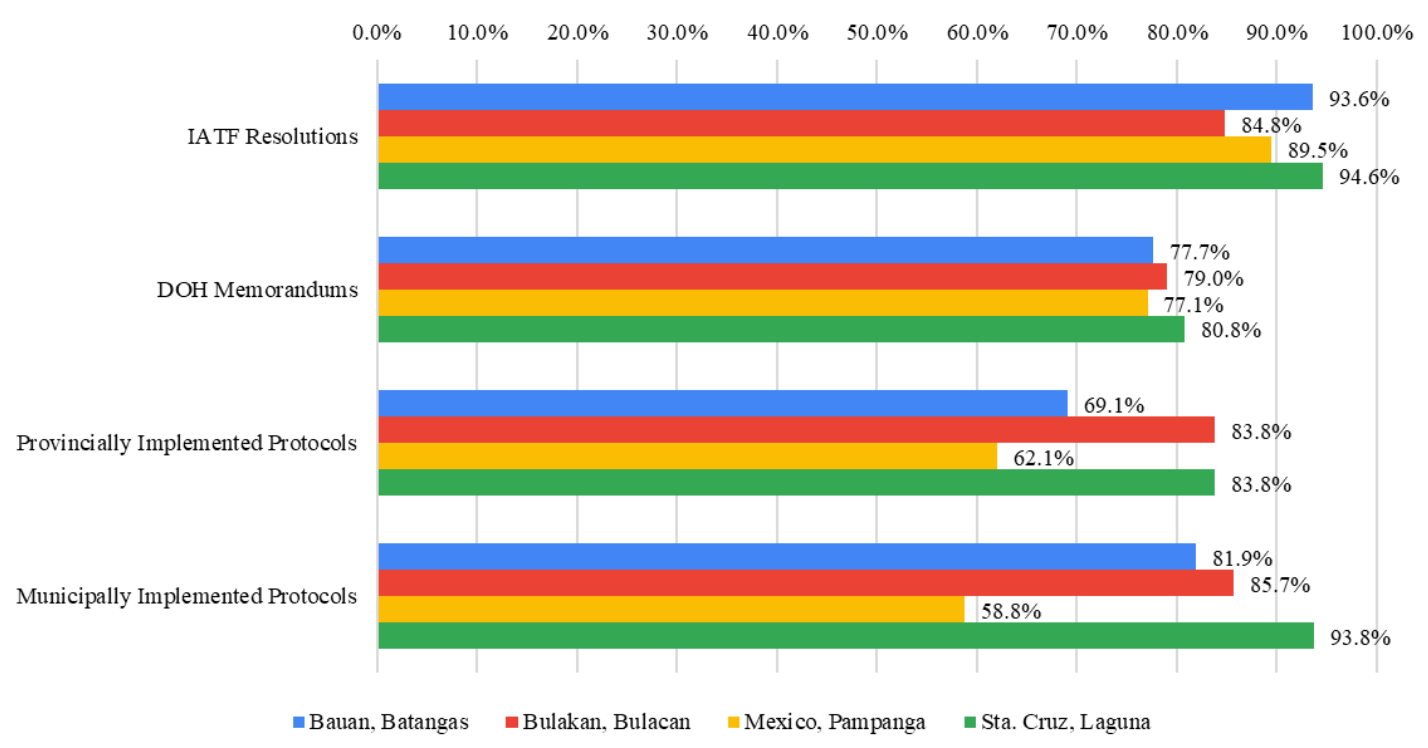

Fig 6. Number of New COVID-19 Cases from the 1st Week of November 2020 to the 1st Week of March 2021

In terms of quarantine and isolation protocols, it can be observed that all four municipalities implemented strict protocols. A combination of systems applied in each municipality including IATF Resolutions, DOH Memorandums, Provincially Implemented Protocols, and Municipally Implemented Protocols. In line with these guidelines, quarantine and isolation facilities are made available for the use of the public. Through the collaborative work of the national and local government, the locations of the existing facilities are made known to the people.

Moreover, all municipalities practice the separation of quarantined individuals from isolated individuals. Furthermore, suspected COVID-19 cases were isolated individually to minimize the risk of transmission. All four municipalities also observed the mandatory two-week quarantine period for asymptomatic cases. Most municipalities only have more or less three quarantine facilities that would cater the needs of both asymptomatic and symptomatic COVID-19 patients. Most of these facilities in all four municipalities are owned or rented by the government. Majority of the healthcare workers in charge of quarantine and isolation facilities did not undergo proper training in regard to the facilitating procedures. However, the proper distribution of tasks is observed in order to limit and minimize the healthcare worker's patient exposure.

For social distancing, wearing of masks and face shields in public places were observed in all four municipalities from Region III and Region IV. Moreover, social distancing measures intended for public establishments such as availability of sanitizing agents in entrances, limitation of number of persons allowed for entry, temperature checks before entry and prohibition of entry for people with temperatures higher than normal were also implemented in all four municipalities. Conversely, three out of four municipalities defined social gatherings to only ten people with the exclusion of Bulakan, Bulacan as it scored a mean rating less than 3.5. Requirement of travel authority passes for intrazonal and interzonal travel were also observed in three out of four municipalities, with the exclusion of Sta. Cruz Laguna as it insufficiently scored on affirmative responses. However, only two municipalities specifically Bauan, Batangas and Mexico, Pampanga observed the implementation of 6-feet distance among people in public places and the implementation of age restricted curfews for individuals aged 15 and below \& 65 and above. Moreover, wearing gloves in public 
places was not implemented in all four municipalities which is deemed a positive finding as wearing gloves increases risk of cross-contamination.

In terms of contact tracing, all of the municipalities from Region III and Region IV-A observed eliciting information regarding direct physical contacts in contact tracing. These municipalities also observed conducting case interviews in conducive and safe environments. Additionally, all of the municipalities maintained data privacy in contact tracing. It is also notable that all of the municipalities used a contact tracing ecosystem, which mostly consisted of BHERTs. Aside from these, the municipalities and the government units, regional line agencies, private sectors, and public sectors collaborated in order to extend the procedures for contact tracing. Healthcare workers were the collaborators employed for contact tracing in all of the municipalities. Lastly, in two or less of the municipalities from Region III and Region IV-A, it can be observed that: contact tracers attended seminars or trainings in contact tracing (Bauan, Batangas and Bulakan, Bulacan); cognitive interviewing strategies in case investigations and manual tracking were used to trace probablesymptomatic and asymptomatic patients; information regarding people who stayed with the case in similar household, places visited, and other information were elicited (Bauan, Batangas and Sta. Cruz, Laguna); interviewers composed the community support team involved in the contact tracing ecosystem (Bauan, Batangas); and law enforcement was the additional collaborators employed for contact tracing (Mexico, Pampanga). None of the municipalities implemented the use of encoders, analysts, and technical support staff in the contact tracing ecosystem; employment of population officers and volunteers for contact tracing; and use of electronic tracking systems and DOH information systems for tracing probable symptomatic and asymptomatic patients.

For testing, all of the municipalities, there were adequate and available resources for COVID-19 testing. On the other hand, in three out of four of the municipalities from Region III and Region IV-A, it can be observed that: government shouldered the fees for testing; if free testing were available, respondents would avail COVID-19 testing; 1-10 million was the established funding for maintaining safety and capacity in testing centers; diagnostic test done in testing centers is the rapid antibody test; and that RT-PCR was used to confirm test results. In two or less of the municipalities from Region III and Region IV-A, the following were observed: mass testing was implemented; tests were readily available and and accessible to every individual; individuals shouldered fees for testing; funds were not established for maintaining safety and capacity in testing centers; modal frequencies of one to two number of recognized testing centers for COVID-19 diagnosis; modal frequencies of $1 \%-25 \%$ patient capacity in the testing centers; reference laboratories were accessible; and rapid antigen tests, pooled tests, and other tests were used in the diagnostic test in testing centers. In terms of collection, handling, and transport of specimens, all of the municipalities have mean ratings above 3.5, hence all of the municipalities strictly adhere to the protocols for specimen collection, handling, and transport.

The closure of establishments was implemented by all of the municipalities included in this study. Those establishments that are non-essential and recreational were required to be closed by all municipal governments. Most businesses including salons, spas, gyms, museums, casinos, and sports venues were closed by all municipalities. Some of the restaurants, specifically in Bulakan, Bulacan remained open. 


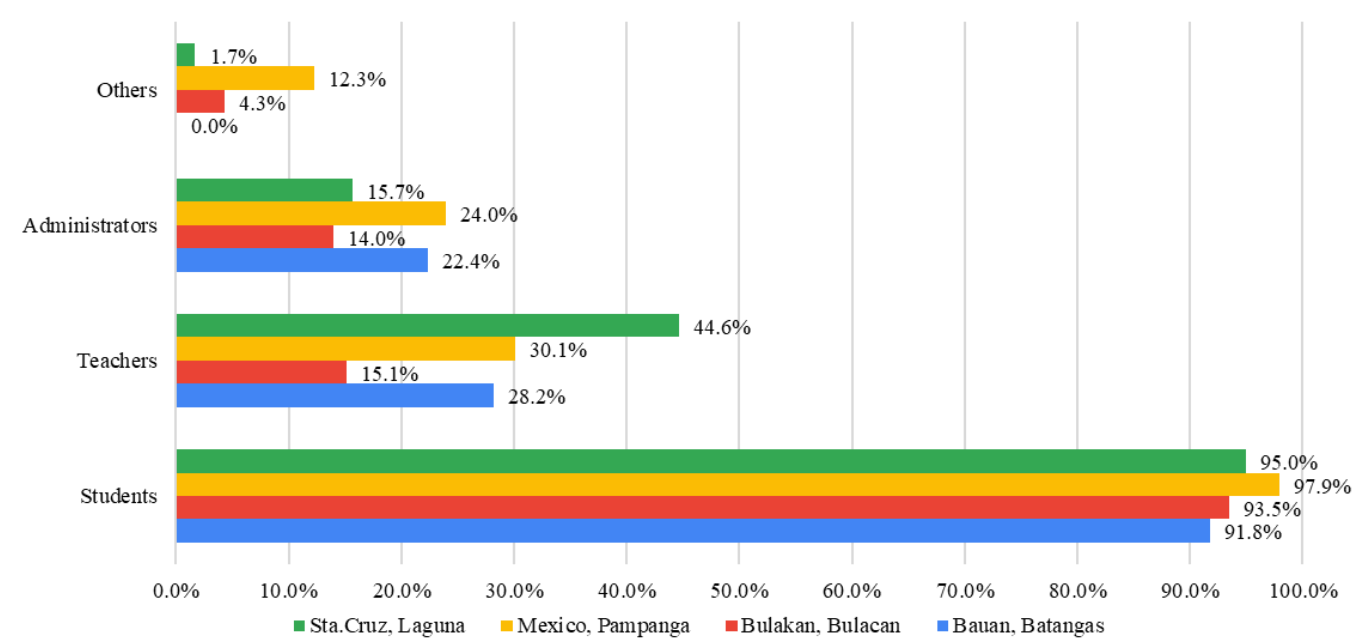

Fig 7. Distribution of Persons Prohibited from Entering School Premises

Based on this figure, entry of school premises was also limited to specific people such as administrators and teachers only. Along with this, all municipalities have strictly prohibited all students from entering their school. Additionally, all municipal governments also reduced the number of workers who need to be physically present in their respective workplaces. Both Sta. Cruz, Laguna and Mexico, Pampanga have required more than half of their workers to be physically present while the other two municipalities only had less than half of their workers.

All four municipal governments are transparent in reporting information, and social media was the main means of dissemination to the constituents whereas websites, flyers, and others are used by two or less of the municipalities. Moreover, information provided by each of the four municipal governments are readily accessible and available for all. In all municipalities from Region III and Region IV-A under study, the following can be observed: a.) giving of food packs to the municipality's constituents during lockdown or enhanced community quarantine; b.) collaboration among regional line agencies, municipal government units, and public and private sectors; c.) particular communication plan addressing different target groups, key messages, necessary materials as well as the distribution strategies to reach the target groups; and d.) development of nationally consistent general information or fact sheets on being prepared with the pandemic to be distributed among the target groups. In terms of the type of communication used among the officials, vertical type or route of communication was utilized by all four municipalities. On the contrary, horizontal and diagonal type of communication was practiced in only 2 or less of the studied municipalities. In addition, having their own budget to provide monetary aid to its people was attributed to all four municipal governments as well as the good allocation of supplies and equipment for frontliners. 


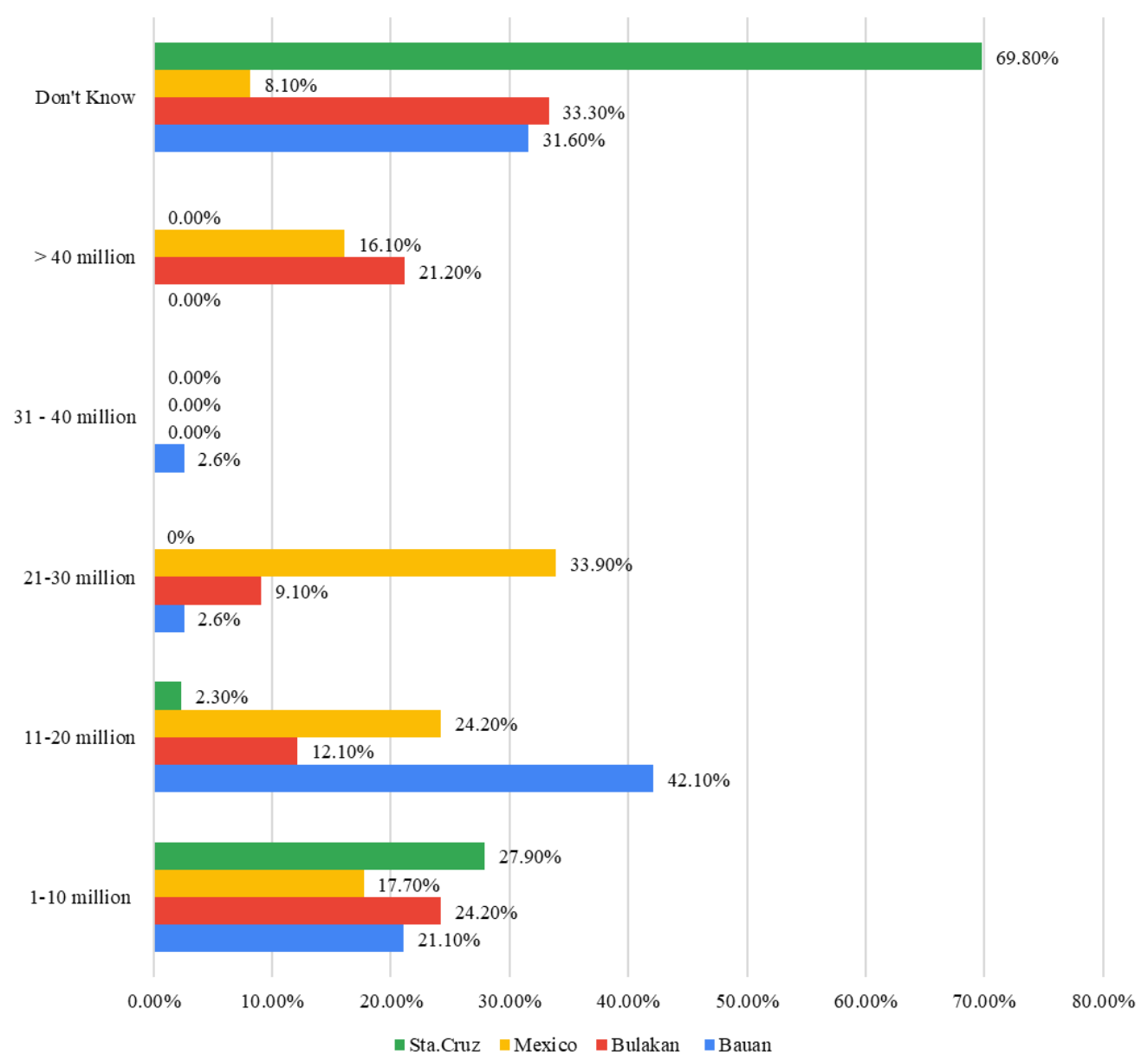

Fig 8. Distribution of Persons Prohibited from Entering School Premises

For finance, the average range of the allocated budget in all of the municipalities is 11 to 20 million with the obtained median of 16 million and mean of 18 million. As for financial aid from other organizations, all municipal governments under study receive this. Excluding Bauan, Batangas, the three municipalities got financial support from non-government organizations. In addition, Bauan, Batangas; Mexico, Pampanga; and Sta. Cruz, Laguna received financial assistance from private sectors/businesses. Only Sta. Cruz, Laguna received financial aid from international partners. With regard to the amount of financial aid received, respondents from the municipalities under study excluding Mexico, Pampanga don't know. Only the municipality of Mexico, Pampanga had stated a certain financial amount received which is 1-10 million.

Bauan, Batangas; Bulakan, Bulacan; Mexico, Pampanga; and Sta. Cruz, Laguna have livelihood sectors allocated or financially supported by the government as well as enough budget for ambulance maintenance and repair, medical transport vehicles, and emergency response vehicles. Alternately, most of the municipalities excluding Sta. Cruz, Laguna had their governments able to purchase enough PPE for frontliners. Lastly, only two or less of the municipalities from Region III and Region IV- A under study 
exhibited the following pandemic strategies which are finance- related: enough equipment, reagents and testing kits (Bulakan, Bulacan and Sta. Cruz, Laguna) ; giving disinfectants, sprayers, disinfection tents, and other disinfecting supplies and misting equipment by the government (Bauan, Batangas and Mexico, Pampanga) ; providing budget for food, transportation (including fuel), and accommodation expenses of frontliners (Bauan, Batangas); enough budget for personnel training in conduct of COVID-19 and other related trainings (Bauan, Batangas); enough budget for the construction, repair, lease, or rental of additional space or building to accommodate COVID-19 patients and patients under monitoring (Bauan, Batangas and Mexico, Pampanga); and enough budget for the maintenance and operation of stand-alone/mobile testing laboratory which was not observed in any municipality.

\subsection{Effective Contact Tracing and Isolation Procedures in Decreasing COVID-19 Transmissions}

Pampanga implement control strategies and intervention that is significantly more effective than Sta. Cruz, Laguna.

The analysis of the new COVID-19 cases in the municipalities under study presented that Week 15 to Week 23, Week 23 to Week 29, and Week 29 to Week 46 demonstrated noticeable changes and marked consistency. For Week 15 to 23, includes first week of June 2020 to first week of September 2020, there is no significant difference $(\mathrm{p}=0.317)$ between the means of the number of new cases of four municipalities. Whereas for Week 23 to 29, from first week of September 2020 to first week of November 2020, there is a significant difference $(\mathrm{p}=0.001)$ between the mean number of new cases of each municipality. The results presented that Bauan, Batangas is significantly different than Mexico, Pampanga and Bulakan, Bulacan. For Week 29 to 46, from first week of November 2020 to the first week of March 2021, there is a significant difference ( $p<0.001)$ between the means of new cases. The mean of new COVID-19 case transmissions of Mexico, Pampanga is significantly different than Sta. Cruz, Laguna, but it had no significant difference with Bauan, Batangas and Bulakan, Bulacan.

The basis of identification of effective contact tracing and isolation procedures based from the responses were the percentages that are high from the municipalities of Bauan, Batangas and Bulakan, Bulacan. In addition, the analysis of the new COVID-19 cases recorded for 46 weeks considered the municipalities of Bauan, Batangas and Mexico, Pampanga.

The effective measures were based from high affirmative scores from the municipalities of Bauan, Batangas and Bulakan, Bulacan. Whereas the quarantine and isolation procedures employed by Mexico, Pampanga were not used as a basis since it has a low rating in this category. The effective contact tracing and isolation procedures in decreasing virus transmissions in the four municipalities included the following: implementation of quarantine and isolation protocols; having an available quarantine and isolation facilities that the public knows of; separation of isolated individuals from quarantined individuals; individual isolation of suspected COVID-19 patients; following the two-week quarantine; having a proper and suitable healthcare facility for testing, isolation, and clinical management; frequent screening of symptoms; and having a trained healthcare worker on handling both asymptomatic and symptomatic patients.

The municipalities of Bauan, Batangas and Mexico, Pampanga had the highest perception rating on contact tracing practices making it the basis for efficacy. Other considerations for inclusion was the rating of Bulakan, Bulacan being the second highest following Bauan, Batangas. Effective contact tracing procedures includes the following: the use of cognitive interviewing strategies in case investigations; collecting information regarding people who had direct physical contact with probable patients in case investigations; conducting interviews in safe and conducive environments; maintaining data privacy; having a contact tracing ecosystem composed of BHERTs; having government units, regional line agencies, and private sectors collaborate; employ healthcare workers for contact tracing; and the use of manual tracking to trace probable symptomatic and asymptomatic patients. 
3.4. Effect of Demographic Factors on the Perception of Residents in the Efficacy and Effectiveness of Control Strategies and Interventions Implemented

The Pearson Chi-Square $\left(\chi^{\wedge} 2\right)$ test statistic value of 2.435 demonstrated that gender was not associated and does not affect the perception of residents in the effectiveness and efficacy of control strategies and interventions implemented in the four municipalities ( $p$-value 0.656). Since there is no association between gender and perception rating from the result of Chi-square test, there is no need to refer to Cramer's V.

Table 7. Association Between Gender and Perception Rating Chi-Square Tests

\begin{tabular}{lccc}
\hline & Value & df & p-value \\
\hline Pearson Chi-Square & $2.435^{\text {a }}$ & 4 & 0.656 \\
Likelihood Ratio & 3.295 & 4 & 0.510 \\
N of Valid Cases & 485 & & \\
\hline a. 5 cells $(55.6 \%)$ have expected count less than 5. The minimum expected count is .01.
\end{tabular}

For age and perception rating, the Pearson Chi-Square $\left(\chi^{2}\right)$ statistic value is 28.434 with a p-value less than 0.001 . With level of significance, $\alpha=0.05$; the null hypothesis that there is no significant association between age and perception rating is rejected. Thus, ratings are dependent on the age group of the respondents. Even though the chi-square test suggested that there is an association between the age and perception ratings, Cramer's V value of 0.242 indicates a moderate association.

Table 8. Association Between Age and Perception Rating Chi-Square Tests

\begin{tabular}{lccc}
\hline & Value & df & p-value \\
\hline Pearson Chi-Square & $28.434^{\mathrm{a}}$ & 4 & $<0.001$ \\
Likelihood Ratio & 28.000 & 4 & $<0.001$ \\
$\mathrm{~N}$ of Valid Cases & 484 & & \\
\hline a. 0 cells $(0.0 \%)$ have expected count less than 5. The minimum expected count is 7.01.
\end{tabular}

Table 9. Association Between Age and Perception Rating Symmetric Measures

\begin{tabular}{llll}
\hline & & Value & p-value \\
\hline Nominal by Nominal & Phi Cramer's V & 0.242 & $<0.001$ \\
& & 0.242 & $<0.001$ \\
N of Valid Cases & & 484 & \\
\hline
\end{tabular}

The association between resident municipality and perception rating is demonstrated in table __, whereby Pearson Chi-Square $\left(\chi^{2}\right)$ statistic value is 27.153 and at $\alpha=0.05$ level of significance, the $p$-value is less than 0.001 . Hence, the null hypothesis that municipality of respondents is not significantly associated with their 
ratings is rejected. This implies that the ratings provided by the respondents is associated in their respective resident municipality. The Cramer's V value of 0.237 indicates the effect size of the association as moderate.

Table 10. Association Between Municipality and Perception Rating Chi-Square Tests

\begin{tabular}{llll}
\hline & Value & df & p-value \\
\hline Pearson Chi-Square & $27.153^{\mathrm{a}}$ & 3 & $<0.001$ \\
Likelihood Ratio & 30.128 & 3 & $<0.001$ \\
N of Valid Cases & 484 & & \\
\hline
\end{tabular}

a. 0 cells $(0.0 \%)$ have expected count less than 5 . The minimum expected count is 12.83 .

Table 11. Association Between Municipality and Perception Rating Symmetric Measures

\begin{tabular}{llll}
\hline & & Value & p-value \\
\hline Nominal by Nominal & Phi Cramer's V & 0.237 & $<0.001$ \\
& & 0.237 & $<0.001$ \\
N of Valid Cases & & 484 &
\end{tabular}

Shown in table __ is the association between occupation and perception rating where Pearson Chi-Square $\left(\chi^{2}\right)$ statistic value is 14.717 and p-value is 0.002 that is less than $\alpha=0.05$ level of significance. Hence, the null hypothesis that occupation of respondents is not significantly associated with their ratings is rejected, implying that the ratings provided by the respondents is associated or dependent to their occupation. The Cramer's V value of 0.174 , however indicates a weak association between the occupation and perception rating.

Table 12. Association Between Occupation and Perception Rating Chi-Square Tests

\begin{tabular}{lccc}
\hline & Value & df & p-value \\
\hline Pearson Chi-Square & $14.717^{\mathrm{a}}$ & 3 & 0.002 \\
Likelihood Ratio & 16.255 & 3 & 0.001 \\
N of Valid Cases & 484 & & \\
\hline a. 0 cells $(0.0 \%)$ have expected count less than 5. The minimum expected count is 5.82.
\end{tabular}

Table 13. Association Between Occupation and Perception Rating Symmetric Measures

\begin{tabular}{llll}
\hline & & Value & p-value \\
\hline Nominal by Nominal & Phi Cramer's V & 0.174 & 0.002 \\
& & 0.174 & 0.002
\end{tabular}


3.5. Suggestions for Improvement in the Implemented Control Strategies and Interventions Implemented in Each of the Municipalities from Region III and Region IV-A

Based on the results in quarantine and isolation, the researchers would like to suggest the following: Proper training and seminars for healthcare workers on facilitating quarantine and isolation procedures; The addition of more quarantine and isolation facilities must be set-up in order to cater for more mild and asymptomatic cases since the capacity of most hospitals are reaching its limit; The municipalities must constantly inform their people regarding the location of these quarantine and isolation facilities; The municipality of Sta. Cruz, Laguna must strictly isolate suspected COVID-19 patients individually; Strict adherence to the two-week quarantine period for both asymptomatic and symptomatic patients; Consistent screening and monitoring of symptoms not only for individuals who travelled but also people who had contact with a patient.

The results obtained reflected the following suggested improvements on the implemented social distancing practices employed by the four municipalities in Region III and Region IV-A: Implementation of 6-ft. distance among people in the public, utilization of quarantine passes, and age-restricted curfew for individuals aged 15 and below \& 65 and above shall be subject for implementation or reinforcement in Bulakan, Bulacan and Sta. Cruz, Laguna; The prohibition of social gathering of more than ten people shall be implemented or reinforced in Bulakan, Bulacan; and requiring of travel authority passes for intrazonal and interzonal travels, except for authorized personnel shall be implemented or reinforced in Sta. Cruz, Laguna.

In terms of contact tracing strategies, the researchers would like to suggest the following: All of the municipalities should conduct seminars and training on contact tracing for contact tracing collaborators; Mexico, Pampanga should use cognitive interview strategies. The rest of the municipalities must constantly adhere to the use of cognitive interview strategies; Information such as people who stayed with the case in the similar household and places visited by these people must be elicited; The use of electronic tracking systems is highly recommended in order to trace probable symptomatic and asymptomatic patients.

With regards to testing, the researchers would like to suggest the following: When possible, conduct mass testing programs. This is highly recommended for the areas with high cases of COVID-19 transmissions; The availability and accessibility of tests to individuals must be ensured; Fees for mass testing should be covered by the government; If possible, increase the number of testing centers; For Mexico, Pampanga, funding should be established for maintaining the capacity and safety of testing centers.

In terms of establishment closure, the researchers would like to suggest the following: Maximize the use of online platforms in conducting academic-related activities to minimize the need for teachers and administrators to physically go to schools; If possible, strictly implement the closure of establishments, especially the non-essential and recreational ones. In Bauan, Batangas, we suggest the closure of salons and museums; Switch to work from home set up to minimize the number of people going to their respective workplaces. The capacity of workers in the workplace, especially in Mexico, Pampanga and Sta. Cruz, Laguna, should be lessened.

Given the results obtained, the researchers would like to suggest the following: Increase funding for Bauan, Batangas and Mexico, Pampanga for free testing; If government spending is allocated to other important matters, ask for financial aid from private sectors; If possible, allocate budget for shelters for the homeless, purchase and distribute vitamins and other essential medicines particularly to the vulnerable groups; and provide enough budget for training of personnel in the conduct of COVID-19 testing and other related activities, for the construction, repair, lease, or rental of additional space or building to accommodate COVID- 
19 patients and persons under monitoring or investigation, and for the maintenance and operation of a standalone/mobile testing laboratory.

\subsection{Other Insights and Significant Statistical Facts Important in Mitigating COVID-19 Transmissions}

The following insights made in quarantine and isolation are the following: The location of the quarantine and isolation facilities are not well-known in Bauan, Batangas and Sta. Cruz, Laguna; The municipalities of Bauan, Batangas; Bulakan, Bulacan; and Mexico, Pampanga excellently implemented the individual isolation of suspected cases; Bauan, Batangas has the highest available capacity for quarantine and isolation facilities; Symptom screening is mostly done twice a day; The tasks among healthcare workers are excellently distributed, except for Mexico, Pampanga., as close as possible to the first reference to them in the paper; and majority of the quarantine and isolation facilities in Bauan, Batangas are owned by private individuals.

Upon assessing the social distancing protocols implemented by the four municipalities, the following insights were deemed worth noting: Four Social Distancing protocols were excellently implemented by Bauan, Batangas. These are wearing masks at all times when in public places, making alcohols or sanitizing agents available in entrances of public places, conducting temperature checks before entering malls, stores, or buildings, and not allowing entry to public establishments of people with temperatures higher than normal (37C); Aside from wearing gloves in public places, Mexico, Pampanga implemented the remaining social distancing protocols well; Four social distancing protocols were implemented excellently or well (i.e. high ratings) from all four municipalities, namely: wearing masks at all times when in public places, making alcohols or sanitizing agents available in entrances of public places, and conducting temperature check before entering malls and not allowing entry to public establishments of people with temperatures higher than normal (37C); Wearing of face shields was well implemented by three municipalities except Bauan, Batangas; and wearing of gloves was rarely observed by all four municipalities.

In terms of establishment closure, the researchers observed that: High percentages of respondents from Mexico, Pampanga required closure in all other establishments in the list except those that were unspecified; Majority of the respondents from the municipalities, except for Bulakan, Bulacan, required restaurants to close; Sta. Cruz, Laguna and Mexico, Pampanga both have very high percentages of respondents who answered that museums were required to close. This shows that both of the municipalities would mean that the closure was implemented just the same; Sta. Cruz, Laguna and Mexico, Pampanga both have very high percentages of respondents who answered that sport venues were required to close. This shows that both of the municipalities would mean that the closure was implemented just the same. 


\subsection{Rating Summary}
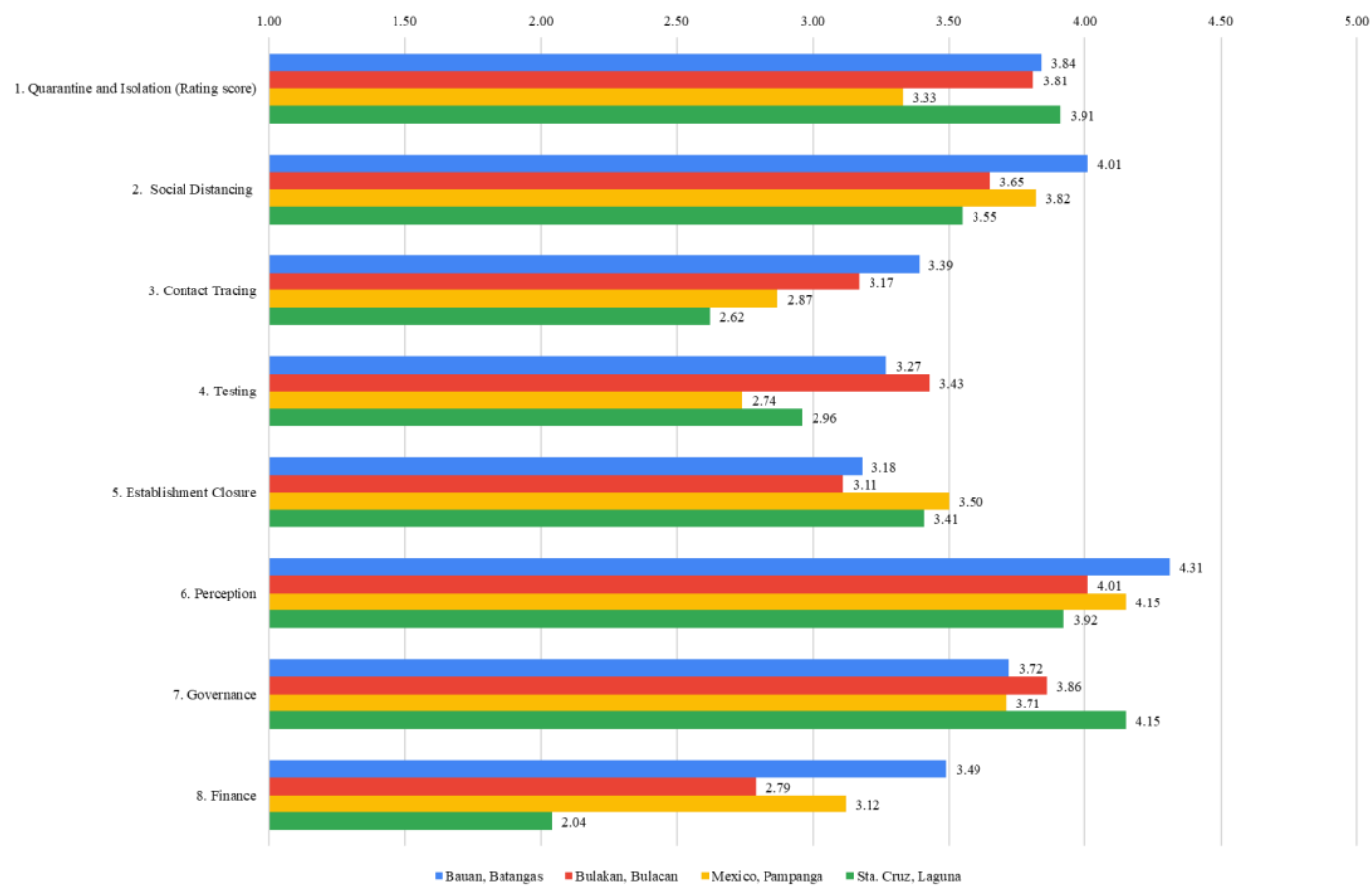

Fig 9. Summary of Rating Distribution of Each Municipality for Each Category

For quarantine and isolation, three municipalities namely Sta. Cruz, Laguna (3.91); Bauan, Batangas (3.84); and Bulakan, Bulacan (3.81) have significantly close ratings compared to Mexico, Pampanga (3.33) with a significant point difference of 0.5 . This suggests that quarantine and isolation protocols present in Mexico, Pampanga is significantly different from other municipalities and has the least transmuted rating. Social distancing practices were well implemented in Bauan, Batangas and Mexico, Pampanga. The municipality of Sta. Cruz, Laguna had the least grand mean rating of 3.55, but it is not significant than that of Bulakan, Bulacan. It can be inferred that Sta. Cruz, Laguna and Bulakan, Bulacan implemented the social distancing practices on average occasion. With F3,485 $=11.5, \mathrm{p}<.0001$ at 0.05 level of significance, the mean rating of Bauan, Batangas is significantly different than Bulakan, Bulacan and Sta. Cruz, Laguna.

On the other hand, in contact tracing, Bauan, Batangas (3.39) had the highest rating in contact tracing, which is followed by Bulakan, Bulacan (3.17). Both Mexico, Pampanga (2.87) and Sta. Cruz, Laguna (2.62) have significantly close rating at the bottom ranks. It can be observed that Bauan, Batangas, being the highest rated municipality in contact tracing, is significantly higher than the ratings of Mexico, Pampanga and Sta. Cruz, Laguna. Bauan, Batangas is the most effective while Sta. Cruz, Laguna is the least effective in contact tracing.

In testing, Bulakan, Bulacan (3.43) had the highest rating followed by Bauan, Batangas (3.27). Both had relatively close ratings. Mexico, Pampanga (2.74) and Sta. Cruz, Laguna (2.96) had relatively close ratings, but significantly less than the ratings of Bauan, Batangas and Bulakan, Bulacan. This suggests that both Bulakan, Bulacan and Bauan, Batangas had ratings that are significantly different than Mexico, Pampanga. Result of the ANOVA on the strict implementation of specimen collection, handling, and transport in the 
testing facility suggests that there are no significant differences in the implementation of four municipalities each with a very high rating. Thus, the variability in the ratings are attributed to other parameters in testing.

In terms of establishment closure, Mexico, Pampanga (3.50) and Sta. Cruz, Laguna (3.41) had relatively close ratings, while Bulakan, Bulacan (3.11) and Bauan, Batangas (3.18) had relatively close ratings. The point difference between the highest rated municipality, Mexico, Pampanga and the lowest rated municipality which is Bulakan, Bulacan is significant. This suggests that Mexico, Pampanga implements the closure of establishments more effectively than Bulakan, Bulacan.

In perception, respondents from Bauan, Batangas (4.31) had the highest mean rating among other municipalities. At 0.05 level of significance with $\mathrm{F} 3,484=10.03$ and $\mathrm{p}<.001$, there is a significant difference between the mean rating of Sta. Cruz, Laguna (3.92) the lowest, with Mexico, Pampanga (4.15). In general, both Bauan, Batangas and Mexico, Pampanga do not differ in terms of the perception of the respondents. Alternately, perception of respondents from both municipalities differ significantly to that of the respondents from Sta. Cruz, Laguna.

For governance, Sta. Cruz, Laguna (4.15) which had the highest rating is significantly different to both Bauan, Batangas (3.72) and Mexico, Pampanga (3.71). This suggests that Sta. Cruz, Laguna had higher percentages of respondents having a positive response with regards to the governance in their municipality, compared to the respondents of the other three municipalities. Also, Bauan, Batangas and Mexico, Pampanga do not differ significantly in terms of governance, but have the lowest ratings regarding governance.

Lastly, in terms of finance, , Bauan, Batangas (3.49) differs significantly to both Sta. Cruz, Laguna (2.04) and Bulakan, Bulacan (2.79). Sta. Cruz, Laguna had the lowest rating in terms of finance, while Bauan, Batangas had the highest rating, followed by Mexico, Pampanga (3.12). Bulakan, Bulacan and Mexico, Pampanga had mean ratings relative close to each other. Although, the 0.75 difference between Sta. Cruz, Laguna and Bulakan, Bulacan must be noted as significant. In general, Sta. Cruz, Laguna having the least rating is significantly low to the ratings of the other three municipalities.

\subsection{Ranking}

Table 14. Ranking of Municipalities

\begin{tabular}{lccccc}
\hline & Bauan, Batangas & Bulakan, Bulacan & Mexico, Pampanga & Sta. Cruz, Laguna & Perfect Score \\
\hline 1. Quarantine and Isolation (Rating score) & 2 & 3 & 4 & 1 & 5 \\
2. Social Distancing & 1 & 3 & 2 & 4 & 5 \\
3. Contact Tracing & 1 & 2 & 3 & 4 & 5 \\
4. Testing & 2 & 1 & 4 & 3 & 5 \\
5. Establishment Closure & 3 & 4 & 1 & 2 & 5 \\
6. Perception & 1 & 3 & 2 & 4 & 5 \\
7. Governance & 4 & 2 & 3 & 4 & 5 \\
8. Finance & 1 & 3 & 2 & 4.00 & 5 \\
\hline \multicolumn{2}{c}{ Average } & 1.00 & 2.00 & 3.00 & 2.88 \\
\hline
\end{tabular}

The ratings of four municipalities in the eight categories of government control strategies and interventions were ranked to determine the strong and weak areas of each municipality. Control strategies and interventions ranked as first and second were considered as strong area, while those with ranks of third and fourth were considered as weak areas. This is show in Table 13. 
Bauan, Batangas has the most number of strong areas. It has six marked strong areas out of the eight categories of control strategies and intervention. These are Quarantine and Isolation, Social Distancing, Contact Tracing, Perception, and Finance. Its weak areas are Governance and Establishment Closure.

Bulakan, Bulacan has three strong areas out of the eight categories of control strategies and intervention. These are contact tracing, testing, and governance. Its weak areas are quarantine and isolation, social distancing, perception, establishment closure, and finance.

Mexico, Pampanga has four strong areas out of eight listed control strategies and intervention categories. These are social distancing, establishment closure, perception, and finance. Its weak areas are quarantine and isolation, contact tracing, testing, and governance. Sta. Cruz, Laguna has the most number of weak areas. It has only two strong areas namely: quarantine and isolation and governance. Its five weak areas out of the eight listed control strategies and interventions categories are social distancing, contact tracing, testing, perception, and finance.

There is a very noticeable difference in the number of strong areas and weak areas between two municipalities: Bauan, Batangas and Sta. Cruz, Laguna. This suggests a significant difference between the control strategies and intervention implemented in Bauan, Batangas and Sta. Cruz, Laguna. The relatively close number of weak areas and strong areas between Mexico, Pampanga and Bulakan, Bulakan suggests that they are somehow not significantly different.

\section{Conclusions}

This study was conducted at four different municipalities from the two regions, Region IV-A and Region III, which had a great number of COVID-19 cases. Analysis of the number of new COVID-19 cases in the municipalities from March 2020 to February 2021 demonstrated noticeable changes and marked consistency. For the 15 th week to the 23 rd week, there is no significant difference between the means of the number of new cases of four municipalities ( $p$-value $=0.317$ ). As for the 23 rd week to the 29 th week, there is a significant difference between the mean number of new cases of each municipality ( $p$ value $=0.001$ ). Mean number of cases of Bauan, Batangas is significantly different than Mexico, Pampanga and Bulakan, Bulacan. Moreover, mean number of new cases Mexico, Pampanga is significantly different than that of Sta. Cruz, Laguna. While for the 29th-46th week, there is significant difference between the means of new cases ( $p$ value $<0.001$ ), where the mean of Bauan, Batangas is significantly different than Bulakan, Bulacan and Sta. Cruz, Laguna. Furthermore, the mean of Mexico, Pampanga is significantly different than the mean of Sta. Cruz, Laguna but not significantly different than Bauan, Batangas and Bulakan, Bulacan. With the varying trends of case transmission from the four municipalities, current control strategies and interventions must be re-assessed. From the four municipalities, 485 respondents were sampled to assess the strategies implemented in the same areas. The ratings of four municipalities in the eight categories of government control strategies and interventions were ranked to determine the strong and weak areas of each municipality. The study revealed that there is a significant difference between the control strategies and interventions implemented in the municipalities of Bauan, Batangas and Sta. Cruz, Laguna while Mexico, Pampanga and Bulakan, Bulacan are not significantly different. Moreover, association between certain demographic factors and their perception ratings on the efficacy and effectiveness of control strategies and interventions was studied. It was revealed that there is a significant association between the age (p-value $<0.001)$ and occupation (p-value, 0.002) of the respondents and their perception on the effectiveness and efficacy of control strategies and interventions in their respective municipalities. Whereas there is no significant association between the gender of the respondents are their perception on the effectiveness and efficacy of control strategies and interventions (p-value, 0.656) in each municipality. 


\section{Recommendations}

In the light of the results gathered and the conclusions derived from the study, the researchers recommend expanding the participants of the study to other municipalities and increasing the sample size of the study. Moreover, if possible, use a different sampling method which entails the random selection of samples from a population to ensure that selection bias is reduced. Finally, future researchers are recommended to produce a qualitative study regarding the variables affecting the effectiveness of quarantine and isolation procedures (i.e., social distancing practices, contact tracing, testing, establishment closure, governance, and finance).

\section{References}

World Health Organization. (2020, April 15). Considerations in adjusting public health and social measures in the context of COVID-19: Interim guidance. Retrieved 26 August 2020, from https://www.who.int/publications/i/item/considerations-in-adjusting-publichealth-and-social-measures-in-the-context-of-covid-19-interim-guidance World Health Organization. (2019). Middle East respiratory syndrome coronavirus (MERS-CoV).

World Health Organization. (2011, November). The classical definition of a pandemic is not elusive.

World Health Organization. (2020). Retrieved 12 April 2021, from https://www.who.int/news/item/13-10-2020-impact-of-covid-19-onpeople's-livelihoods-their-health-and-our-food-systems

Kohlscheen, E., Mojon, B., \& Rees, D. (2020). The macroeconomic spillover effects of the pandemic on the global economy. BIS Bulletins, 4, 1-2. https://www.bis.org/publ/bisbull04.pdf

Rivas, R. (2020, April 8). What the Philippine economy could be like after the coronavirus. https://www.rappler.com/newsbreak/indepth/what-philippine-economy-could-be-like-after-coronavirus

Techaphangam, N. (2020, May 20). Thai airways files for bankruptcy protection to rehabilitate its business. https://www.ttgasia.com/2020/05/20/thai-airways-files-for-bankruptcy-protection-to-rehabilitate-its-business/

Roberton, T., Carter, E.D., Chou, V.B., Stegmuller, A.R., Jackson, B.D., \& Tam, Y. (2020, May 12). Early estimates of the indirect effects of the COVID-19 pandemic on maternal and child mortality in low-income and middle-income countries: a modelling study. Retrieved 26 August 2020, from https://doi.org/10.1016/S2214-109X(20)30229-1

Yee, J. (2020, July 29). Hospitals running out of COVID-19 Beds - doh. Retrieved February 03, 2021, from https://newsinfo.inquirer.net/1313657/doh-warns-hospitals-running-out-of-covid-19-beds

Ghebreyesus, T. A., \& Swaminathan, S. (2020). Scientists are sprinting to outpace the novel coronavirus. The Lancet, 395(10226), 762764.

Pan American Health Organization (2020). Recommendations to expand access to hand washing and its proper use. Retrieved December 22, 2020, from https://www.paho.org/en/documents/recommendations-expand-access-hand-washing-and-its-proper-use

Esguerra, D. (2020). PH now has the most COVID-19 cases in Southeast Asia. Retrieved 26 August 2020, from https://www. inquirer.net/190091/ph-now-has-most-covid-19-cases-in-southeast-asia

Prasetayo, Y. T., Castillo, A. M., Salonga, L. J., Sia, J. A., \& Seneta, J. A. (2020). Factors affecting perceived effectiveness of COVID-19 prevention measures among Filipinos during Enhanced Community Quarantine in Luzon, Philippines: Integrating ProtectionMotivation Theory and extended Theory of Planned Behavior. International Journal of Infectious Diseases, 99, $312-323$. https://doi.org/10.1016/j.ijid.2020.07.074

\section{Acknowledgements}

This paper would not have been possible without the exceptional support of different people. We would like to extend our sincere gratitude to all of them.

First and foremost, our group would like to express our deepest appreciation to our thesis adviser, Assoc. Prof. Ma. Frieda Z. Hapan, PhD of the University of Santo Tomas for her patience, continuous support and guidance in the accomplishment of this study. Her persistent enthusiasm and immense knowledge helped us to consistently work towards finishing this paper.

We would also like to thank Prof. Aleth Therese L. Dacanay, PhD, dean of the Faculty of Pharmacy, for giving us the opportunity to immerse ourselves in the field of medical technology in the hope of being able to contribute not only to our chosen field, but to the field of medicine in general. 
We are also grateful for our statisticians, Mr. Simon Ogbac and Mr. Rod Anthony, for their valuable comments and suggestions that helped us better understand the knowledge necessary for refining our research.

To our classmates and peer reviewers, we thank you for sharing your insights and suggestions which helped us improve our paper.

Thank you to our dear respondents, who willingly shared information, with the best of their knowledge, to provide necessary information in completing this study.

We would also like to extend our gratitude to the University of Santo Tomas, for allowing us to access different resources that helped us support our data to further improve our work.

Most of all, we would like to thank God, for allowing us to strive through the current situation and for giving us the opportunity to enrich our knowledge by showering us with blessings and resources, despite the pandemic, that helped us bring our work to completion.

To our dear readers, thank you for devoting your time, appreciation and interest in our study. Thank you for inspiring us to be able to come up with this paper. 